\title{
EVIDENCE OF DOCTORS' HEALTH MINISTER AT LAST
}

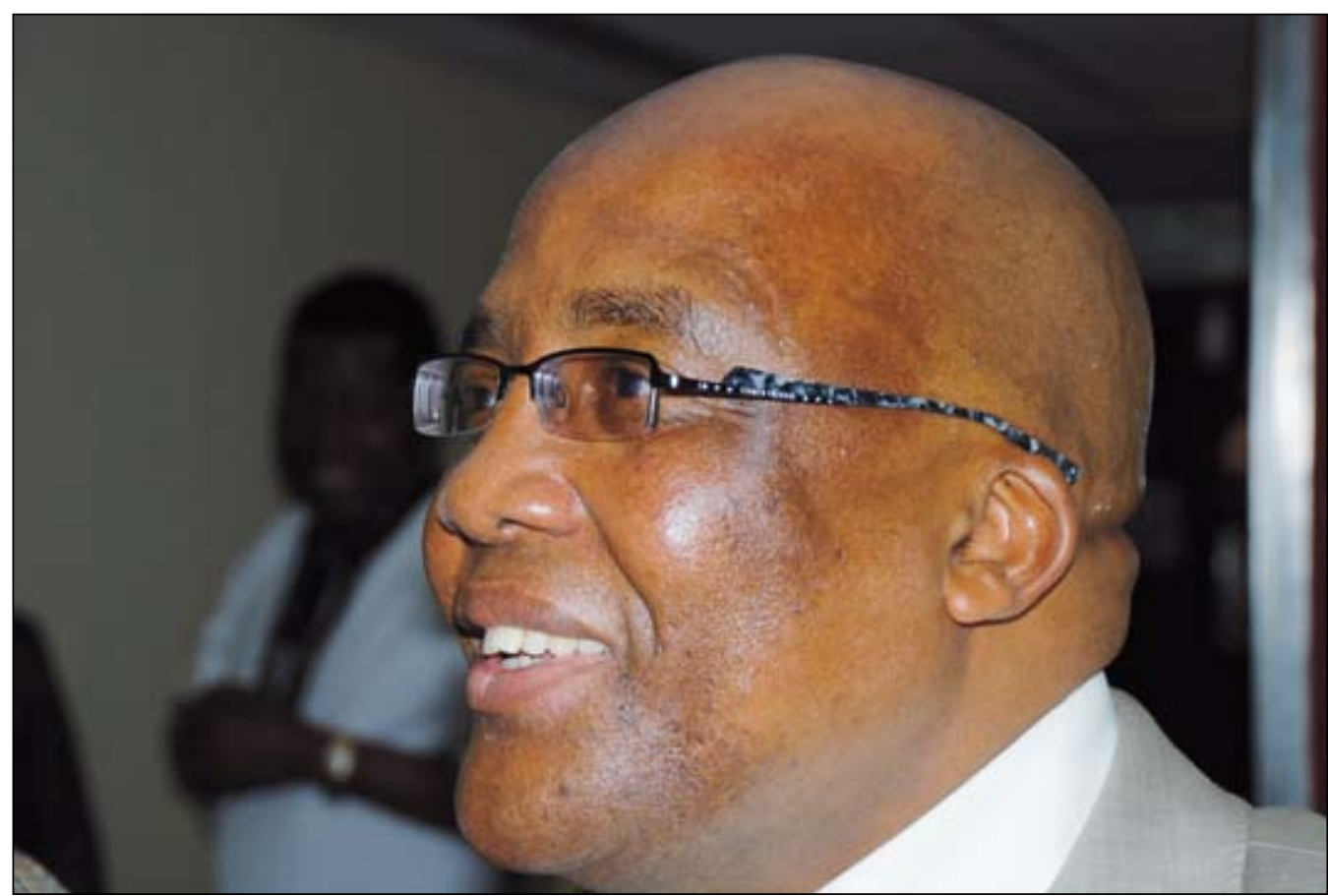

National Health Minister, Dr Aaron Motsoaledi after addressing doctors at the University of Cape Town.

Fragmented health care services are responsible for South Africa's dismal infant and maternal mortality rates while budgets are being greedily consumed by bloated and inefficient administrations that sideline clinicians at the coalface.

New Health Minister Dr Aaron Motsoaledi said this to 200 doctors at Groote Schuur Hospital while sharing how he plans to turn the floundering health care ship around after 'discovering that problems went much deeper than I realised'.

In an address none of his audience dreamed possible during the debilitating tenure of his long-standing predecessor, Dr Manto Tshabalala-Msimang, Motsoaledi outdid some of his department's detractors in sharing horror stories.

He said doctors should never have to think about striking again and gave his audience 'a guarantee that I won't force you to go to the edge - up to today nobody's been able to tell me why the OSD was not implemented last year (2008).

'Journalists say that with the exception of the Western Cape, the whole health system has collapsed. There's no oxygen there, no theatre gloves here .... We read about patients being
Picture: Chris Bateman

left in hot baths, heaters left on and burning them, patients lost in the premises and found dead ... it would be foolhardy to challenge these stories, because in most cases they're true.'

As importantly, he shared in some detail what he's done and what he plans to do to address them, shocking into momentary silence the most hardened cynics and offering hope to the 'Manto-weary' among his mainly public sector audience.

Motsoaledi was invited to address the doctors by the South African Medical Association (SAMA) during the bruising occupationspecific dispensation (OSD) negotiations in June and July last year. He was speaking on 23 November.

He said doctors should never have to think about striking again and gave his audience 'a guarantee that I won't force you to go to the edge - up to today nobody's been able to tell me why the OSD was not implemented last year (2008).

One doctor said that 'nowhere' in the department's human resources plan was there 'ever any consideration or mention of recruiting the amount of doctors we are currently losing in the system' and asked how he planned to address this.

Motsoaledi appealed to his colleagues to help him 'recruit doctors back here', but said he believed the solution lay in 'creating as much as we can locally' (training more doctors).

He said he was hamstrung by the Southern African Development Community (SADC) countries protocol preventing recruitment from most African countries. He was last August 'attacked as the culprit' at an SADC meeting in Kigali, Rwanda, for 'stealing doctors'.

'We debated charging countries for every doctor going to the First World but agreed this wouldn't work, so we ended up resolving to ask First World countries for more money to train locally,' he said. 


\section{'Nobody thought about human resources'}

In a strong criticism of the previous health regime, Motsoaledi said he was amazed that 'it seems nobody was thinking about' the development and management of human resources.

The percentage growth of administrators versus clinical officers 'is just abnormal', he admitted. If he could get 'just $10 \%$ of those people out of the offices' and replace them with clinicians, morale and patient care would immediately improve.

'In this economic meltdown they were saying certain posts can't be filled - but out at the coalface it's wrong to freeze anything. You can freeze administrative posts, but not at the coalface. The percentage growth of administrators versus clinical officers 'is just abnormal', he admitted. If he could get 'just $10 \%$ of those people out of the offices' and replace them with clinicians, morale and patient care would immediately improve.

'It's a very abnormal situation ... freezing posts at hospitals while at all administrative offices no posts are frozen. If a director is not working they hire two more and then they get into conflict with one another and cancel each other out,' he added to laughter.

A 15-month Development Bank probe of the health (and educational) system, begun in February 2008 under former RDP minister Jay Naidoo, showed that 'we're filling offices and leaving clinics empty'.

It also produced alarming graphs of how South Africa was spending more money for lesser health care outcomes than equivalent developing countries, while failing to reduce infant mortality.

Motsoaledi said it was time the country returned to health care basics instead of just throwing money at problems.

During October and November last year a team of top UNAIDS professionals toured most of the country's HIV, TB and reproductive facilities to see how they could best be integrated into more efficient 'one visit' facilities. The report was due on his desk in December 2009.

With $40 \%$ of maternal deaths caused by HIV, he questioned why testing and prevention of mother-to-child transmission was not being done at hospitals.

'Also we have HIV/TB co-infection at $73 \%$ but nothing is integrated, nobody in a rural area will visit the next facility. When you look at the high HIV prevalence provinces like KwaZulu-Natal and Mpumalanga the TB cure rate is just 40\%.'

\section{Health care delivered in disease 'silos'}

Provinces complained of not having enough antiretroviral sites, yet official site accreditation required dieticians, psychologists, the likes of which he'd not seen in any rural hospital.

'It means we're saying we want to do this for the next 100 years. Why for example can I, with an MB ChB, not examine and treat a woman who's been raped? We create unnecessary barriers.'

Motsoaledi revealed that on 21 and 22 November 2009 he called together all his hospital CEOs, clinical managers and nursing chiefs for an unprecedented feedback session. He told them they would be audited (for, inter alia, the National Health Insurance (NHI) implementation this year) on 6 points.

'You could see it was long overdue - some of them had the answers ... but nobody had been listening.'

Embarrassingly for him, the first point of order was the cleanliness of hospitals.

'I have yet to meet a family where the father and mother and the children sit down to discuss how dirty the house is, but that's what I did last week,' he joked, shaking his head.

Staff attitude was a strong second point because 'where everyone is miserable, nobody gets better'.

Even though clinical staff sometimes worked 16 straight hours in difficult conditions, their attitude towards their patients was paramount. Besides the safety and security of patients, infection control was a major issue, one he has publicly admitted renders many hospitals 'veritable death traps'.

Motsoaledi said he was determined to
bring back the redoubtable health inspector,
'now known as environmental health
officers', citing the preventable local cholera
outbreaks in Messina in Limpopo Province
early last year.
'The way our health system works is you
get sick first and then you find us waiting
at hospital ... something has gone terribly
wrong,' he added.

Several hospitals had unqualified people in charge of infection control, not to mention junior nurses or clerks actually running the hospital. Hospital managers would however only be judged on performance during assessments, he added.

While government would shoulder responsibility for drug shortages, in many cases these were the fault of the hospital manager when, for example, 'warehouses stand full of drugs'. 
He had made a compact with hospital CEOs that when drug supplies ran dangerously low, they would warn him in time.

Long queues in hospitals were often due simply to poor management of patients and dysfunctional clinics, 3000 of which had been built since 1994 .

\section{NHI critics miss the prevention bus}

He was tired of hearing so-called experts making cost estimates on the NHI, based on a curative system.

'They all think the war is about how to put a person in a private hospital with curative medicine with all the gadgets ... that we can actually have primary health care and prevent diseases, nobody speaks about.'

Unnecessary referrals sometimes meant somebody with a small cut on their hand was sent by a clinic to a public hospital where they queued for 8 hours.

Motsoaledi said he was determined to bring back the redoubtable health inspector, 'now known as environmental health officers', citing the preventable local cholera outbreaks in Messina in Limpopo Province early last year.

'The way our health system works is you get sick first and then you find us waiting at hospital ... something has gone terribly wrong,' he added.

One hospital manager had told him there were supposed to be 36 health inspectors in his area but he had yet to find out what a single one did.

'The way our health system works is you get sick first and then you find us waiting at hospital ... something has gone terribly wrong,' he added.

A major overhaul was also needed to prevent shopkeepers and hawkers doing what they wanted and municipalities allowing raw sewage to flow in the streets.

He instructed his hospital managers to 'each sit down and develop a programme' for their hospitals by January this year.

\section{Doctors must safeguard independence}

Responding to a question about a new law giving him the power to appoint the majority of members to the Health Professions Council of South Africa (HPCSA) (introduced during Tshabalala-Msimang's reign), Motsoaledi said doctors should do more to safeguard their independence.

\section{Another survey by a major commercial bank promoting maths and science found that when the country's 6000 schools were asked how many of them could pass 100 learners in higher grade, only 13 qualified. All these schools were either in Cape Town, Durban, Johannesburg or Pretoria.}

The controversial former president of the HPCSA (Professor Nicky Padayachee) was now an official in his department, as was a former registrar of the Medicines Control Council (which has a 7-year medicine registration backlog).

'It's wrong, you can't allow this to happen. You need independent people on these things - lawyers would never allow a deputy director-general in the justice department to be Chief Justice,' he added.

Told by one audience member that only $18 \%$ of the annual 100000 crop of matrics were allowed into universities, making it nigh impossible to find appropriate medical recruits, Motsoaledi revealed a frightening statistic of his own. The Development Bank diagnosis on education included a survey of 52 African countries in which South Africa was rated last in mathematics ability among its pupils. Another survey by a major commercial bank promoting maths and science found that when the country's 6000 schools were asked how many of them could pass 100 learners in higher grade, only 13 qualified. All these schools were either in Cape Town, Durban, Johannesburg or Pretoria.

'The other provinces have nothing - all this impacts on the health care system.' Motsoaledi emphasised that, as with the assessment of his hospital managers, he had 'singled out only the weak points' in his address.

'That's how you get things done,' he added.

Motsoaledi promised mid-level public sector doctors, badly done in by the OSD settlement last June, that 'we've approached treasury and by mid-April the problem will be solved,' adding 'please just don't leave'!

\section{Chris Bateman}

